\title{
THE MARKET FOR POLITIES AND THE CONSUMER CITIZEN: Applying Microeconomics to National Sovereignties
}

\author{
Octavian-Dragomir Jora, \\ Associate Professor, Ph.D.The Bucharest University of Economic Studies \\ Matei-Alexandru Apăvăloaei, \\ Assistant, Ph.D.The Bucharest University of Economic Studies \\ Mihaela lacob, \\ Assistant Professor, Ph.D.The Bucharest University of Economic Studies
}

\begin{abstract}
Within polities, the prosperity or welfare of citizens (as consumers of public goods and services) is supposed to stem, depending on the (ideo)logical bias of the narrator, either from generously allowed degrees of individual liberty or from tightly centrally-planned levels of societal security (or from some optimum "trade-off", or from some "golden-ratio" mixture of the two features). Further colouring this picture, it is noteworthy that while the advocates of the "freedom" route rely on common-sense, natural-law definition, defence, and disposition of private property rights, the apostles of "safety" commandments equate them with egalitarian redistributive justice with respect to earnings and accumulations or with conservative management of statuses and fortunes. Irrespective of the dominant view, the fact that the political order delivering such liberty/security pays tribute to a sovereign (be it some heavenly-anointed king or the earthly will of the people) looks fishy at least for classical economists. They rightly ask how such monopoly-sovereigns could be incentivized to be less costly and more caring relative to the citizens-as-consumers. This paper aims to apply basic (micro)economic judgments to the problem of disciplining sovereignties/states, in fact their political agents/administrators, in delivering the truly needed public goods: i.e., from the material/physical infrastructure to the symbolic/institutional one. However, the neoclassical framework will be duly exposed as rather inappropriate for the job. Instead, we will appeal to the praxeological insights (of classical pedigree, thoroughly revamped along with the subjectivist and marginalist revolutions in economics) on entrepreneurship and competition. On the one hand, we will address the process of intra-polity competition, among domestic political entrepreneurs (eventually united in political parties) and observe the limits of its working. On the other hand, we will assess the mechanisms of inter-polities (international) competition, the embodiments they take (secession, migration), with all the historical taboos they do embitter. The thesis is that inter-polities competition is more citizen-/consumer-friendly than the intra-polity one, since it is not merely about controlling a status quo, but about challenging it.
\end{abstract}

Keywords: state; public goods; monopoly; institutional competition; praxeology

$$
\text { Ww } W \text {. I C B M E C N F. Org }
$$

